\title{
A Balanced Approach to the Teaching of Intermediate-Level Writing Skills to EFL Students
}

\author{
Xinyu Qian \\ School of Foreign Languages, Jiangsu University \\ Zhenjiang 212013, China \\ E-mail: xinyuqian.au@gmail.com
}

\begin{abstract}
By analyzing the shortcomings of the traditional approach and the drawbacks of the modern approach, the author attempts to explore a better way for the teaching of intermediate-level writing skills to EFL students. Taking into account all of the factors which are involved in good writing, the author puts forward a balanced approach to such teaching and provides some principles and techniques for the classroom procedures in which the balanced approach is applied.
\end{abstract}

Keywords: Traditional approach, Modern approach, A balanced approach

\section{Introduction}

Since the theory of "communicative competence" was advanced by Hymes, it has to a great extent encouraged and enlightened many linguists who are not satisfied with the analysis of language merely based on its structures and forms. So communicative teaching approach gradually came into being. Nowadays, it has been generally admitted that the communicative teaching approach has some merits in the improvement of learners' communicative competence. As one aspect of the communicative competence, the ability of writing can also be greatly improved through this approach. However, the communicative approach is not the cure-all, and it also has some defects of its own. So in the practice of the teaching of writing skills to EFL students, we'd better seek an approach which comprises the advantages of both the traditional and the modern teaching approaches. In the following passage, we will try to explore such an approach based on the analysis of the traditional and the modern approaches to the teaching of intermediate-level writing skills to EFL students.

\section{The traditional approach}

The most influential approach of the traditional methods of organizing language teaching is that of the 3Ps: presentation, practice, and production. The first stage is generally focused on a single point of grammar which is presented explicitly or implicitly to maximize the chances that the underlying rule will be understood and internalized. This would essentially aim at the development of declarative knowledge. This initial stage would be followed by practice activities, designed to automatize the newly grasped rule, and to convert declarative to procedural knowledge. And at the production stage the degree of control and support would be reduced, and the learner would be required to produce language more spontaneously, based on meanings the learner himself or herself would want to express.

Reflected in the teaching of writing at the inter-mediate level in foreign-language classrooms, such an approach often appears as the teaching of basic sentence-level writing skills, with organizational skills added. In basic writing training, often a student is given an example sentence whose meaning is explained; then the grammar pattern is taught; finally, the student is asked to write similar sentences using different content. At the intermediate level, the student is given an example paragraph to read; the overall organizational pattern of the paragraph is explicated; finally, the student is told to write a similar paragraph about a different subject. For example, students might be given a paragraph to read in which two people are compared in terms of physical characteristics. Then the teacher will demonstrate the patterns for comparing the attributes or characteristics of things at the sentence level, and the overall organizational pattern of a paragraph of comparison, followed by exercises for practice. Finally, the students might be asked to write a paragraph of their own comparing two of their friends in terms of physical characteristics. This is the traditional "read-analyze-write" approach.

Practitioners of the modern approach to writing point out that the traditional approach is deficient in two important respects. First, the teacher views the student's writing as a product. She assumes that the student knows how to write and uses what the student produces as a test of that ability. Second, the teacher focuses on form, i. e., syntax, grammar, mechanics, and organization, rather than on content. The content is seen mainly as a vehicle for the correct expression of the grammatical and organizational patterns taught, and the correct choice of vocabulary. 


\section{The modern approach}

In 1970's, directed against Chomsky's "linguistic competence", Hymes put forward the theory of "communicative competence". Based on this theory, the "communicative approach" gradually came in fashion. This approach concentrates on getting learners to do things with language, to express concepts and to carry out communicative acts of various kinds. The content of a language course is now defined not in terms of forms, words and sentence patterns, but in terms of the concepts, or notions, which such forms are used to express, and the communicative functions which they are used to perform.

Reflected in the teaching of intermediate-level writing skills to EFL students, the modern approach involves a combination of the communicative approach and the process approach to writing. It is based on three assumptions:

A. People write to communicate with readers.

B. People write to accomplish specific purpose.

C. Writing is a complex process.

Thus, writing is seen as a communicative act. Students are asked to think of their audience, the reader, and their purpose for writing. Meaning is stressed, rather than form. And writing is seen as a process, which can be divided into three stages: prewriting, composing, and revision. Students are trained to use the methods that good writers use in writing.

The communicative approach has its own problems in the following two aspects. First, it turns out that learners don't very readily infer knowledge of the language system from their communicative activities. Second, when using language indexically either to convey our intended meaning, or to interpret the meanings of other people, we adopt strategies of differential access and analysis in the interests of effective communication. So inevitably, there are some problems with trying to apply the approach of teaching intermediate-level writing skills to EFL students to practice. The two major problems are as follows. First, the overwhelming majority of findings in the research into the process of writing deal with students who write at an advanced level. Next to nothing is recorded about the application of these findings to basic and intermediate writing programs in EFL countries. Second, the research into the grammatical improvement of students who use the process method of learning to write shows no improvement at all.

\section{A balanced approach to the teaching of intermediate-level writing skills to EFL students}

Because both of the approaches are deficient in themselves (although it has been generally accepted that there are lots of merits in the communicative teaching approach), we practitioners should take both into consideration in the teaching of intermediate-level writing skills to EFL students. As Ann Raimes points out that "all approaches to writing overlap, and the teacher should not be so devoted to one approach that she excludes all others." (1) A teacher should be eclectic, drawing from all methods available. A balanced approach to the teaching of intermediate writing skills should take into account all of the factors which are involved in good writing. The diagram below shows what writers have to deal with as they produce a piece of writing.

Insert Figure 1 Here

Students need to think about the interests, knowledge, and abilities of the people they are writing for and the purpose for which they are writing. They need to learn the value of writing several drafts and developing their ideas. Raimes points out that "a student who is given the time for the process to work, along with the appropriate feedback from readers such as the teacher or other students, will discover new ideas, new sentences, and new words as he plans, writes a first draft, and revises what he has written for a second draft. "(2)

But students also need to learn the styles and formats for a variety of writing purposes, and the grammatical and lexical terms relevant to those purposes as well. In addition, they need to be trained to act as an audience for other writers and to comment on the logicality, factualness, and appropriacy of what a writer puts down on paper as well as the form in which he does it.

For the balanced approach discussed above, I would like to suggest that classroom procedures for such an approach make use of the following principles and techniques.

A. Even though language learning is divided into four skill areas, i.e., reading, writing, listening, and speaking, the skills should not be treated in total isolation of each other. Thus, although writing is the focus of attention in the writing classroom, it should always be supported by other skills.

B. The students should do as much of the work as possible, not the teacher. The teacher's role is to advise on 
procedures and to monitor the work that is going on.

C. Students should work together on a lot of the activities through pair and group work. Discussion is important in generating and organizing ideas and for discovering what it is that the writer wants to say, even though the actual writing may be done individually(3)

D. When pair or group work is used, the teacher should monitor it carefully to see that it is proceeding smoothly. On-the-spot correction and advice can be provided as appropriate. Although a lot of self-evaluation should be built in, students will want to have feedback on what they have written. However, this should be done after the students have tried to correct their work themselves.

E. Students should be asked to exchange their compositions so that they become readers of each other's work. This is an important part of the writing experience because it is by responding as readers that students will develop an awareness of the fact that a writer is producing something to be read by someone else(4). And through analyzing and commenting on another person's work, they will develop the ability read their own writing critically.

F. In correcting work, the teacher should:

a). Introduce a correction code with symbols for the different types of errors; e. g., p for punctuation errors, voc for poor choice of word, etc. This encourages students to use their communicative competence, that is, the information inside their head, to correct their own mistakes, or to ask questions to put them right.

b). Focus on global rather than local errors. That is, attend to errors that interfere with comprehensibility rather than errors that have little effect on the reader's ability to understand. In general, global errors involve poor sentence and paragraph organization, omitting needed information, misuse (including omission) of sentence linkers and logical connectors, breakdown in tense concord across sentences, and ambiguity of reference (including relative pronouns)(5).

c). Let students know how successful they have been in achieving the aims of the task by including a short overall comment(6).

\section{Conclusion}

The elements of the program described above constitute what we consider to be a balanced approach to the teaching of intermediate-level writing skills for EFL students. This approach, in my opinion, will be quite favorable both to teachers and to students who are involved with it.

\section{Appendixes}

Appendix One: Characteristics of good writing materials

For the approach discussed above, I would like to propose the following principles as guidelines for choosing, designing, or adapting materials for the teaching of intermediate-level writing skills in EFL countries.

A. Materials should be learning-centered rather than teaching-centered. They should focus on helping students to develop their own strategies for learning.

B. Materials should be creative. They should provide stimulating activities to focus students' attention on the things to be learned. Audiovisual aids such as tapes, pictures, and diagrams should be used to activate the students' awareness of the content as something real.

C. Materials should be interesting. They should be related to students' interests. Moreover, there should be a variety of text types and activity types in the materials to motivate the students' interest in writing.

D. Materials should be task-based. They should use purposeful tasks to motivate students' learning and to make students see the usefulness of writing.

E. Materials should be practical. They should deal with real-life communication tasks.

Appendix Two: Unit components

Each unit of a writing course should concentrate on one type of writing activity; for example, a letter of complaint, an accident report, etc. All the activities in the unit should lead up to the final writing activity. Here is one way that the activities in a unit can be organized so that a student is fully prepared to do the final writing task.

A. Input. The unit should begin with a reading passage that is a good example of the type of writing you want the student to be able to produce. This closed reading passage is used to provide content that is shared by all students in the classroom. It provides subject matter for discussion and for composition topics. Students become familiar 
with the vocabulary, idioms, sentence patterns, and organization used. The students can learn a great deal about writing from the closed reading.

B. Language Practice. After seeing an example of the types of language used in the reading passage, students can be given training in the production of the grammar, vocabulary, and organization needed for the writing purpose. This training is provided in four parts:

a. Language summary. Students study charts which display the language patterns and use many of the vocabulary terms that apply to the type of writing taught.

b. Controlled writing. Students are given exercises in which a great deal of the content and/or form is supplied. The student's job is, for example, to fill in the missing information or to manipulate the order of the content.

c. Outline. The student is presented with one or more patterns for the overall organization of a passage of the type of writing being studied. This is often followed by guided writing practice.

d. Guide writing. This provides further practice using the grammatical points or syntactic structures taught in the language summary, but gives the student more freedom to use the vocabulary, idioms, ideas, and organization introduced in the reading passage. This leads up to the relatively free writing of the student's final writing activity.

C. Semi-free Writing. This is a type of activity in which the students, singly or in pairs or in a group, use their own ideas to write a passage, although the ideas are controlled by the purpose that the teacher provides and by the need to use the grammatical and/or syntactic patterns taught in the unit.

D. Revision. After the composition is written, it will be given to another student or other students who make comments on the content and form. Then it is rewritten and submitted to the teacher for her comments. After the students revise the second draft, the third draft is handed in to the teacher as the final product.

\section{References}

Hymes, D. (1972) On Communicative Competence. In Sociolinguistics. Eds. J. B. Pride and J. Holmes Harmondsworth: Penguin

Nolasco, Robert. (1987). Writing: Upper Intermediate. Oxford: Oxford University Press.

Raimes, Ann. (1983). Techniques in Teaching Writing. New York: Oxford University Press.

White, Ron. (1987). Writing: Advanced. Oxford: Oxford University Press.

Skehan, Peter. (1998). A Cognitive Approach to Language Learning. Oxford: Oxford University Press.

Widdowson, H.G. (1991). Aspects of Language Teaching. Oxford: Oxford University Press.

Wilkson, D. A. (1976). Notional Syllabuses [M]. Oxford: Oxford University Press.

\section{Notes}

Note 1. Ann Raimes, Techniques in Teaching Writing. New York, Oxford University Press, 1983, 11

Note 2. Raimes 76

Note 3. Ron White, Writing: Advanced. Oxford, Ox-ford University Press, 1987

Note 4. White

Note 5. White

Note 6. Robert Nolasco, Writing: Upper Intermediate. Oxford: Oxford University Press, 1987

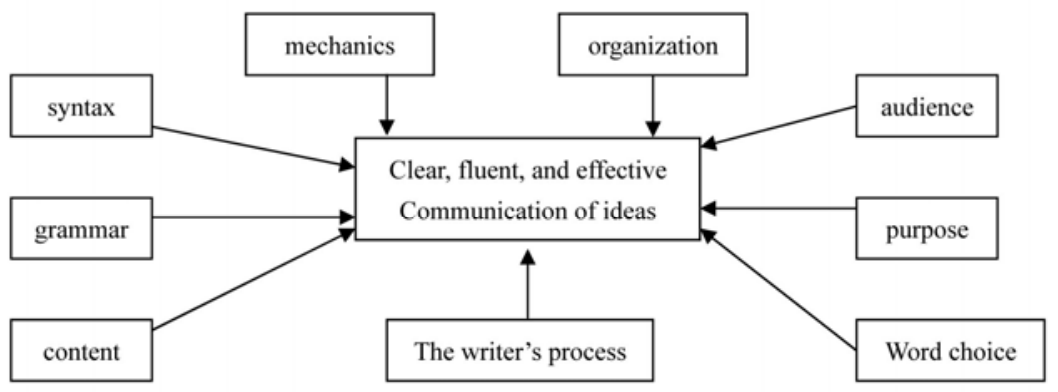

